\title{
Correction: B7-H4 as an independent prognostic indicator of cancer patients: a meta-analysis
}

\section{Zibo Meng ${ }^{1, *}$, Feiyang Wang ${ }^{1, *}$, Yushun Zhang ${ }^{1}$, Shoukang Li ${ }^{1}$ and Heshui Wu ${ }^{1}$}

${ }^{1}$ Department of Pancreatic Surgery, Union Hospital, Tongji Medical College, Huazhong University of Science and Technology, Wuhan 430022, China

* These authors contribute equally to this work

Published: February 26, 2018

Copyright: Meng et al. This is an open-access article distributed under the terms of the Creative Commons Attribution License 3.0 (CC BY 3.0), which permits unrestricted use, distribution, and reproduction in any medium, provided the original author and source are credited.

This article has been corrected: The proper name of the institution is as follows:

${ }^{1}$ Department of Pancreatic Surgery, Union Hospital, Tongji Medical College, Huazhong University of Science and Technology, Wuhan 430022, China

Original article: Oncotarget. 2017; 8:68825-68836. https://doi.org/10.18632/oncotarget.18566 